\title{
An unusual cause of phlegmonous appendicitis, actinomycosis: a case report
}

\begin{abstract}
Background: Acute appendicitis is the most common condition requiring emergency abdominal surgery. The etiology is multifactorial but obstruction of the appendicitis lumen and infectious agents are important in pathophysiology. Actinomycosis appendicitis is an uncommon disease and also extremely rare. In this article, we present a case who was operated for acute abdomen, underwent right hemicolectomy and reported actinoymcosis appendicitis as the result of pathology.
\end{abstract}

Case presentation: A 46 year-old man was referred to our centre with abdominal pain. In abdominal examination right lower quadrant tenderness, defense and rebound detected. In abdominal ultrasonography showed that an aperistaltic, non compressible, distended appendix with pericecal inflammatory changes. So the patient was scheduled to open surgery. Perioperative ileocecal mass, mesenteric multiple lymph adenopathies detected and right hemicolectomy performed. The postoperative course of patient was uneventful and he was discharged at the tenth days. The pathology result of the specimen was reported as actinoymcosis appendicitis.

Conclusion: Actinomycosis appendicitis is uncommon and extremely rare. Clinical, laboratory radiological differential diagnosis is quite difficult. It should be kept in mind in acute appendicitis in ileocecal mass.

Keywords: Actinomycosis, acute, appendicitis, emergency, pain, case report
Volume 10 Issue 2 - 2019

\author{
Erdem Obuz,' Ramazan Serdar Arslan, ${ }^{2}$ Sirin \\ Kucuk $^{3}$ \\ 'Department of General Surgery, Esme State Hospital,Turkey \\ ${ }^{2}$ Department of General Surgery, Banaz State Hospital, Turkey \\ ${ }^{3}$ Department of Pathology, The Faculty of Medicine, Usak \\ Universty, Turkey
}

Correspondence: Ramazan Serdar Arslan, MD, Banaz State Hospital, Department of General Surgery, 64500, Banaz, Usak, Turkey,Tel +90 5053037447, Email r.serdar.arsIn@gmail.com, r.arsin@saglik.gov.tr

Received: March 03, 2019 | Published: April 03, 2019

\section{Introduction}

Acute appendicitis is one of the most common causes of acute abdomen, incidence reported to be between 8.6 and 11.7 per $10,000 .{ }^{1}$ The etiology is multifactorial but obstruction of the appendiceal lumen, increased luminal pressure and impaired circulation cause bacterial propagation and increased mucus induces the inflammatory response physiopathological process. ${ }^{2}$ Lymphoid hyperplasia, fecaloid, foreign materials, tumors, and parasites causes obstruction of appendiceal lumen. ${ }^{2}$ Escherichia coli was the most common microorganism in the microbial assessments. Pseudomonas aeruginosa, Klebsiella pneumonia are the other common gram negative pathogens. ${ }^{3}$ Enterococcus species, streptococcus species and staphylococcus aureus are the common gram positive pathogens. ${ }^{4}$ Fungal and parasitic appendicitis is rare. The prevalence and incidence of actinomycocis appendicitis is not clear. It is reported, that actinomycetes are the etiology of appendicitis in only $0.02 \%-0.06 \% .^{4-6}$ Actinomyces are slow growing, non-spore forming, gram positive, branching bacteria that thrive in anaerobic and microaereophilic conditions. Actinomyces is part of the normal flora of oral, cervicofacial regions, respiratory tract, female genital organ, and gastrointestinal system..$^{2,7}$ Actinomyces is mostly affect ileocecal area in gastrointestinal tract. Actinomycosis can be seen as ileocecal masses and appendicitis.?

\section{Case presentation}

An 46 year-old man was referred to our centre with abdominal pain. In abdominal examination right lower quadrant tenderness, defense and rebound detected. The laboratory findings were: white blood cell count $16.2 \times 10^{\wedge 3} / \mathrm{uL}$ (Normal, 4.0 to 10.0), neutrophil count $14.7 \times 10^{\wedge 3} / \mathrm{uL}$, C-reactive protein level (CRP) $114 \mathrm{mg} / \mathrm{L}$ (Normal, 0 to $5 \mathrm{mg} / \mathrm{L}$ ), aspartate transaminase (AST), $65 \mathrm{U} / \mathrm{L}$ (Normal, 10 to $37 \mathrm{U} / \mathrm{L}$ ). Ultrasonography (US) was performed because there was no computerized tomography $(\mathrm{CT})$ in the hospital. In abdominal US showed that an aperistaltic, non compressible, distended appendix with pericecal inflammatory changes. Appendix diameter measured $16 \mathrm{~mm}$. In his history he had bilateral pneumonectomy due to lung aspergillus six years ago. As a result of examination radiology and laboratory tests, the patient was scheduled to operation with the diagnosis of acute appendicitis. Mc Burney incision used for surgery with spinal anesthesia. Multiple lymphadenopathy in mesentery and a mass in junction of caecum and appendix were palpated during surgery (Figure 1), so decided to oncological right hemicolectomy. Incision is extended medially and laterally. Right hemicolectomy and side to side ileocolic anastomosis was performed. A silicone drain was placed in the pelvic and right paracolic areas. The postoperative course of patient was uneventful. Oral nutritional started at fourth day and drains removed sixth day. The patient was discharged from the hospital on the tenth postoperative day without any problems.

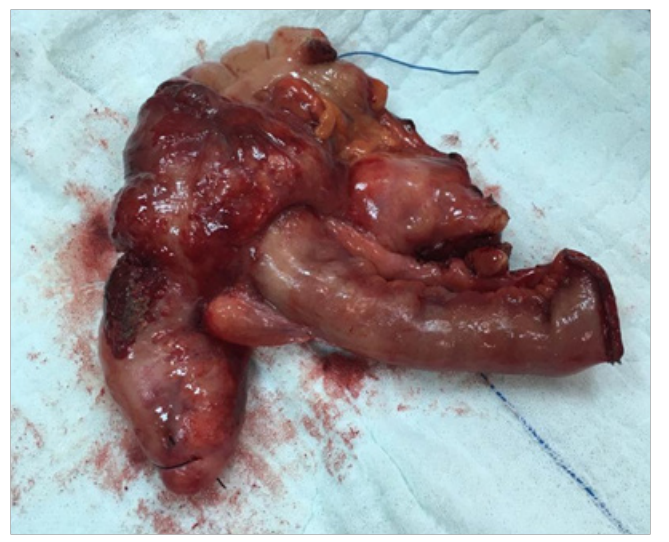

Figure I Surgical specimen. 


\section{Final diagnosis}

The pathology result of the specimen was reported as right hemicolectomy, phlegmonous appendicitis, localize peritonitis, abscess formation and reactive lymph nodes. Diagnosis of actinomycosis of the appendix was established histologically. Typical histologically, the microorganism forms actinomycotic granules (sulfur granules) and these are made of relatively round bacterial aggregations surrounded by eosinophilic material. Microscopic examination of our case revealed acute phlegmonous appendicitis, peritonitis and actinomyces sulfur granules scattered in the purulent exudate in the appendiceal lumen (hematoxylin and eosin (H\&E), $\times 2$ magnification) (Figure 2-5).

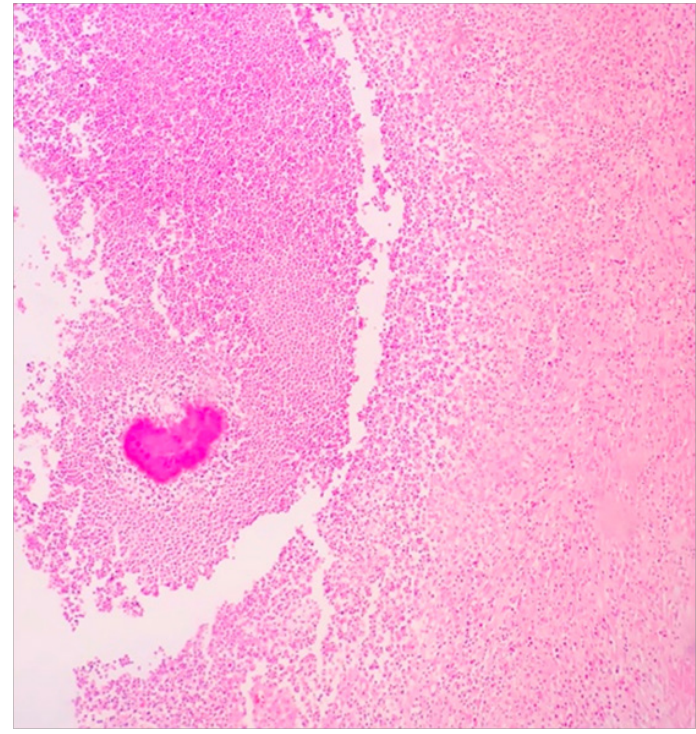

Figure 2 A colony of actinomycosis in the widespread inflammatory cel infiltration site(HEx40).

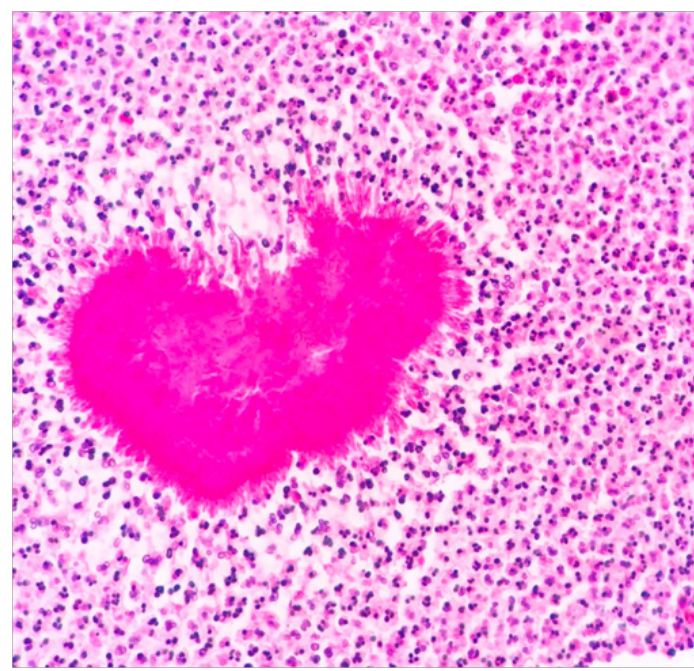

Figure 3 Colonies of actinomycosis showing branching filaments in the center of the abscess formation formed by neutrophils (HExI00).

\section{Outcome and follow up}

The patient had an uneventful postoperative clinical course. After 4 weeks crystalline penicillin $\mathrm{G}$ treatment, he continued taking oral penicillin for five months.

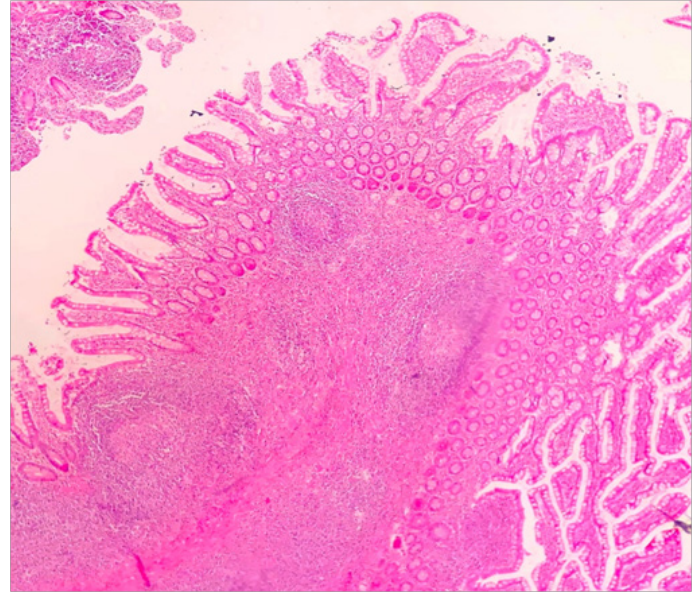

Figure 4 Phlegmonous appendicitis consisting of neutrophilic infiltration in the appendix wall and serosa.

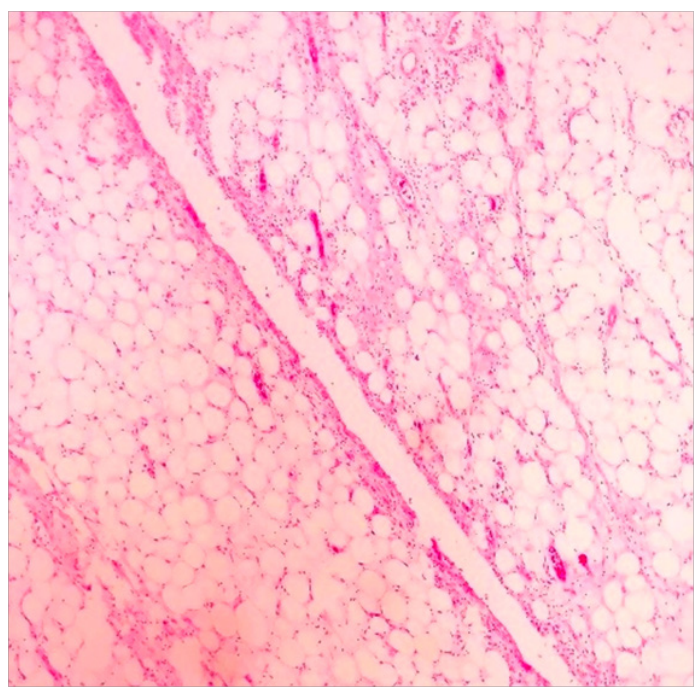

Figure 5 Localized peritonitis with acute inflammatory cell infiltrations (HExI00)).

\section{Discussion}

Actinomyces are normal commensals of the oral cavity, gastrointestinal, urogenital tracts in human body. When the mucosa barrier is broken, actinomycosis becomes pathogenic and causes a subacute-chronic granulomatous bacterial infection that affects soft tissues and internal organs. ${ }^{7}$ There are 13 different species of actinomycosis; six of which are associated with human disease (israelii, naeslundii, bovis, odontolyticus, viscosus and arachnia propionica) ${ }^{8,9}$ Actinomycosis is rare with an incidence between $1 / 300,000$ and $1 / 1,000,000 .{ }^{8,9}$ In gastrointestinal tractus, appendix and ileocaecal region appear to be most commonly involved. ${ }^{8,9}$ Predisposing factors of actinomycosis include neoplasia, poor oral hygiene. There is no predisposing factor in our case. Affected periappendiceal area is surrounded by dense fibrous tissue, and the disease can mimic malignant diseases due to this mass appearance. ${ }^{10}$ There are no specific, clinical, laboratory and radiological findings of appendix actinomycosis. The disease mimicking acute appendicitis is usually very difficult and often impossible to diagnose preoperatively. ${ }^{11}$ When there is no mass or abscess in ileocecal area radiological investigations are often nondiagnostic. Actinomycosis diagnosis is often made with intraoperative 
or postoperative histopathological examination..$^{6-8}$ Histologically, the microorganism forms actinomycotic granules (sulfur granules). These are made of irregular round bacterial aggregations surrounded by eosinophilic material and they are typical for the disease. But sulfur granules are not pathognomonic for actinomycosis. They can also occur in nocardiosis, botryomycosis and aspergillus infections. ${ }^{8}$ In our case, diagnosis was possible by observation of the typical sulfur granules detected during histopathological examination. ${ }^{12}$ Treatment of the appendiceal or abdominal actinomycosis is combination of well antibiotics and surgical resection. The preferred antibiotic treatment includes high-dose crystalline penicillin G (2-4 weeks) and consequent long-term (6-12 months) oral penicillin or semi-synthetic penicillin derivatives. ${ }^{6-9}$

\section{Conclusion}

Actinomycosis appendicitis is uncommon and rarely. The clinical laboratory and radiological findings are similar to other etiologies of appendicitis. It should be kept in mind in acute appendicitis in ileocecal mass patients.

\section{Author contribution}

Obuz E; Study concept, writing the paper, final decision to publish, data collection, manuscript drafting; Arslan RS; Study concept, data collection, writing the paper, final decision to publish; Kucuk S; Data collection, analysis, writing paper.

\section{Informed consent statement}

Informed written consent was obtained from the patient for publication of this report and any accompanying images.

\section{Acknowledgments}

None.

\section{Conflicts of interest}

The authors declare that they have no conflicts of interest.

\section{References}

1. Chen CY, Chen YC, Pu HN, et al. Bacteriology of acute appendicitis and its implication for the use of prophylactic antibiotics. Surg Infect. 2012;13(6):383-390.

2. Yardimci VH, Yardimci AH. Is appendectomy always adequate for treatment?: Clinical manifestations of isolated actinomycosis in the appendix. Turk J Surg. 2018;28:1-4.

3. Lamps LW. Infectious Causes of Appendicitis. Infect Dis Clin North Am. 2010;24(4):995-1018.

4. Song DW, Park BK, Suh SW, et al. Bacterial culture and antibiotic susceptibility in patients with acute appendicitis. Int $J$ Colorectal Dis. 2018;33(4):441-447.

5. Charfi S, Sellami A, Affes A, et al. Histopathological findings in appendectomy specimens: a study of 24,697 cases. Int J Colorectal Dis. 2014;29(8):1009-1012.

6. Alemayehu H, Snyder CL, St Peter SD, et al. Incidence and outcomes of unexpected pathology findings after appendectomy. J Pediatr Surg. 2014;49(9):1390-1393.

7. Liu K, Joseph D, Lai K, et al. Abdominal actinomycosis presenting as appendicitis: two case reports and review. JSurg Case Rep. 2016;2016(5).

8. Wong VK, Turmezei T, Weston V. Actinomycosis. BMJ. 2011;343:d6099.

9. Sergent F, Marpeau L. Abdominopelvic actinomycosis: a tumoral syndrome due to bacterial infection. J Chir (Paris). 2004;14:150-156.

10. Triantopoulou C, Van der Molen A, Van Es A, et al. Abdominopelvic actinomycosis: spectrum of imaging findings and common mimickers. Acta Radiol Short Rep. 2014;3(2):1-5.

11. Bittencourt JA, Andreis EL, Lima EL, et al. Actinomycosis simulating malignant large bowel obstruction. Braz J Infect Dis. 2004;8:186-189.

12. Paritsky M, Cherepnin L. Abdominal actinomycosis mimicking chronic appendicitis. J Clin Case Rep. 2012;2:14. 